\title{
THE IDENTITY OF A SUPPOSED HUMAN MOLAR FROM THE WELLINGTON CAVES OF NEW SOUTH WALES.
}

\author{
By H. H. Finlayson. \\ (Plates xii-xiii; and Figure 1.)
}

In 1870 appeared the first publication of the finding by Gerard Krefft(1) of a portion of a human molar tooth in the Wellington Caves of New South Wales. After a period of uncertainty as to the exact circumstances of the find it was established that the fragment, though developed from its matrix shortly after its discovery, was originally embedded in the characteristic cave breccia in association with extinct marsupials such as Diprotodon and Thylacoleo at a period estimated by David ${ }^{(5)}$ to be from 7,000 to 12,000 years ago.

Since its first identification the fossil has been written upon at greater or less length by Krefft $^{(2)}$ in 1874, Etheridge, ${ }^{(3)} 1890$ (who quotes the opinion of Pedley), Etheridge $^{(4)}$ 1916, David(5) 1923 , and Anderson ${ }^{(6)} 1933$, all of whom have apparently accepted the human origin of the fragment, and Anderson's remark (op. cit.) that "it is one of the best pieces of evidence as to the early existence of man in Australia" embodies a view which seems to have been very generally accepted.

In a recent re-examination of the tooth by Dr. T. D. Campbell (i) its human relationships have been strongly contraindicated and at his suggestion $\mathrm{I}$ have considered de novo its possible relation to the lower mammals. To this end the morphology of the fragment and the type and sequence of the attrition which has produced its crown pattern have been minutely compared with all indigenous Australian mammals, with all introduced and domestic mammals, and with many exotic species as well, which could possibly yield a dental fragment of the size of the fossil. As a result there would now appear no reasonable doubt that the fossil is derived from the Pleistocene macropod Macropus (Protemnodon) anak Owen, a giant "Wallaby", remains of which are already known from the Wellington Caves, and which also occur in profusion in beds of similar and earlier age over a large part of eastern and southeastern Australia.

Preliminary consideration of the general dental anatomy of the fossil brings one to conclusions which have an important bearing on the subsequent examination of its detail.

Regarded as a molar, its outstanding peculiarities are, firstly, its extreme functional brachydonty and, secondly, the simultaneous presence in juxtaposition upon the occlusal surface of large exposures of dentine, with broad major enamel features. While both these conditions may be found separately in several groups of mammals, their concurrence in one species is generally precluded by the structural ground plan of the tooth. In the great majority of molars reduction of the enamel of the wall of the crown to the relative level which obtains in the fossil, simultaneously reduces the occlusal surface to a featureless expanse of dentine, while the few forms among the polyprotodont marsupials and lower carnivores, in which the requisite degree of brachydonty pre-exists, are incapable of yielding the occlusal surface.

This fundamental peculiarity in the structure of the fragment early led the writer to abandon the "molar theory" of its origin altogether. On transferring attention to premolar teeth, close analogies in ground plan were discovered amongst the $3 \mathrm{rd}$ and 4 th 